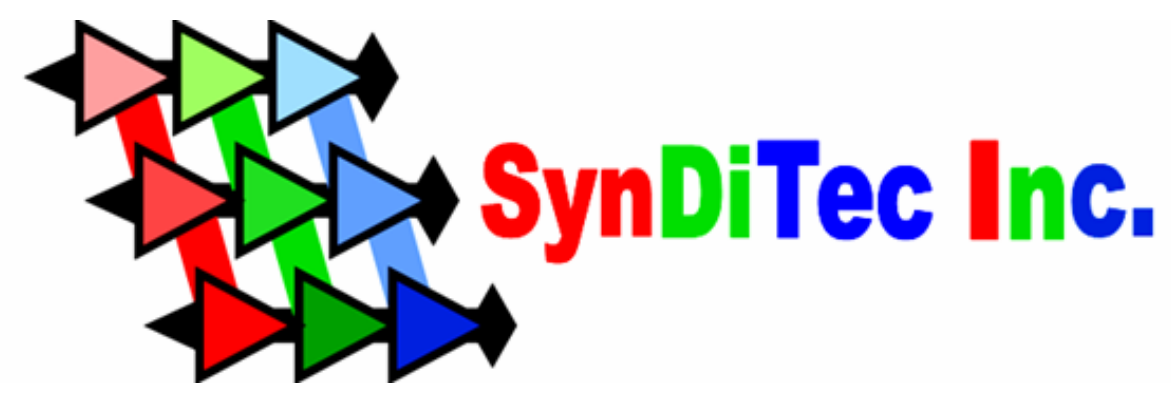

Final Scientific/Technical Phase I Report

On

\title{
Sliding Mode Pulsed Current Averaging IC Drivers for High-Brightness Light Emitting Diodes
}

\author{
August 17, 2006 \\ DOE Grant Number : DE-FG02-05ER86261 \\ Name of Recipient : SynDiTec Inc. \\ Principal Investigator : Dr. Anatoly Shteynberg, SynDiTec Inc. \\ Subcontractor : Dr. Brad Lehman, Northeastern University \\ Business Official : Mr. Harry Rodriguez \\ Prepared by \\ Anatoly Shteynberg, Ph.D \\ 408-448-3100 \\ ashteynberg@synditec.com
}

SynDiTec Inc., 3535 Ross Avenue, Suite 308, Building- II San Jose, CA-95124

Voice: 408-448-3100; Email: harry@synditec.com, Web: http://synditec.tripod.com 


\section{Executive Summary}

This project developed new Light Emitting Diode (LED) driver ICs associated with specific (uniquely operated) switching power supplies that optimize performance for High Brightness LEDs (HB-LEDs). The drivers utilize a digital control core with a newly developed nonlinear, hysteretic/sliding mode controller with mixed-signal processing. The drivers are flexible enough to allow both traditional microprocessor interface as well as other options such as "on the fly" adjustment of color and brightness. Some other unique features of the newly developed drivers include

- AC Power Factor Correction;

- High power efficiency;

- Substantially fewer external components should be required, leading to substantial reduction of Bill of Materials (BOM).

Thus, the LED drivers developed in this research : optimize LED performance by increasing power efficiency and power factor. Perhaps more remarkably, the LED drivers provide this improved performance at substantially reduced costs compared to the present LED power electronic driver circuits. Since one of the barriers to market penetration for HB-LEDs (in particular "white" light LEDs) is cost/lumen, this research makes important contributions in helping the advancement of SSL consumer acceptance and usage.

US Department of Energy projects, a potential reduction of electricity used for illumination could be up to $50 \%$ by 2025 if SSL becomes widespread. Benefits of this would be $>10^{15}$ Wh of electrical power savings, which would lead to a reduction of an almost 1 Billion tons of Carbon dioxide emission (among many other significant emission reductions). Presently, however, the cost/lumen for SSL is prohibitively high for market penetration into the general white light illumination market. This project aids in reducing the cost of SSL High Brightness white lighting systems. It was developed a LED driving pulsed average sliding mode digital controllers. The drivers require no additional expensive circuits that are currently being used for systems with similar features. 


\section{Comparison of Phase I Accomplishments with Original Project Goals}

\subsection{PHASE I Overview}

Phase I research designed, analytically validated, and simulated SynDiTec's newly developed digital hysteretic/sliding mode pulse averaged adaptive controllers for specific application to HB-LEDs. The controllers are based on a proprietary pulsed-current averaging method that is able to predict and subsequently regulate the output current of several types of DC/DC converters, such as boost, buck-boost, flyback, etc. The following technical highlights are the Phase I achieved results :

1. Analytical development of a nonlinear hysteretic sliding mode mixed signal IC controller for high brightness LED driver. Unique to the approach is that SynDiTec's proprietary digital hysteretic/sliding mode controller does not require any A/D or D/A converters, despite its digital implementation. Because of this, cost analysis shows that the BOM for the developed approach is $40 \%-60 \%$ less than comparable technology on the market.

2. LED driver systems, using the pulsed-current IC control algorithms, were shown to be globally asymptotically stable and robust to variations in LED on resistances and conducting voltages. Both theoretical analysis and extensive numerical simulations verify their outstanding performance in terms of: relative stability, robustness to mismodeled dynamics (???), power factor, total harmonic distortion and power efficiency.

3. Block diagram/analytic design of next generation driver IC systems for driving HBLEDs were developed for applications with both DC voltage input and AC-mains.

4. Control algorithms were synthesized written in VHDL and were uploaded into a Xilinx PLD (similar to FPGA). A prototype proof-of-concept prototype LED driving system was built for DC input. The working prototype shows, beyond a reasonable doubt, that the sliding mode controllers can successfully drive LED lamps.

In summary, Phase I research has successfully demonstrated proof-of concept for SynDiTec's adaptive pulsed-current averaging method for HB-LED driving systems and has further demonstrated significant advantages of the approach over known technologies.

\subsection{Phase I Research Objectives vs. Actual Accomplishments}

Phase I research focused on creating theory and engineering methodology for designing highly economical digital LED drivers. At the end of Phase I, the project goal was to establish whether SynDiTec's newly developed digital engine can be utilized with sliding mode controllers for HB LED applications. Specifically, Phase I developed the following 4 deliverables as objectives:

Objective 1. Block diagram and analytical design of an IC driver HB-LED system. 
This Objective 1 has been achieved: Block diagram and analytical design of an IC driver HB-LED system has been developed for both (i) DC voltage input source and (ii) ACmains as input source. Furthermore, the drivers and algorithms were modeled and verified with VHDL on the Simplorer simulator.

Objective 2. Analytical development and feasibility analysis of a nonlinear hysteretic sliding mode derived for a digital controller based on a newly developed pulsed averaging technique.

This Objective 2 has been achieved: First, accurate models in state space for the dynamic behavior of a High Brightness - LED (HB-LED) arrays were developed. These models can be substituted into any power electronic PWM converter when the loads are HBLEDs. By extracting parameters from manufacturer data sheets according to the bin of the HB-LED, ranges model uncertainty can be derived.

Next, we synthesized mathematical models and derived algorithms for pulse current averaging. Unusual to hysteretic control, the new SynDiTec "pulsed current averaged" controllers restrict the amount that a duty ratio in a power electronic switching converter can increase each switching time cycle. Simulations and analysis show that this has the effect to reduce the subharmonic oscillations that normally occur in on/off hysteretic control. In both simulation and theory, the pulsed current averaging IC drivers are shown to be: globally asymptotically stable, robust to unknown modeled dynamics, and have low sensitivity to changing environmental/operating conditions.

Objective 3. Simulations of the digital hysteretic controllers as applied to HB LED systems with DC input and with AC Mains.

This Objective 3 has been achieved: First, we simulated the SynDiTec actual controllers for a boost converter with DC input, using two separate software packages: MATLAB and Simplorer. Using these simulations, we have created: time domain simulations, phase plane analysis, and sensitivity simulations to model uncertainties. The results verified that the pulse current averaging method can be implemented with substantially lower Bill of Materials compared to existing technology, has perfect regulation, high power efficiency, and excellent dynamic and stability performance.

Next, the digital sliding mode controllers were implemented in simulation on Simplorer for two separate topologies that have AC Mains as the input. In this case, a comparison of benefits was made between the buck-boost converter and a single switch two stage converter. Simulations show in both cases that the digital implementation of SynDiTec's pulsed current averaging controllers has excellent performance: zero steady state error regulation for desired output LED current, near unity power factor, and extremely high total harmonic distortion. The two-stage converter has lower capacitor value requirements, giving it advantages (we believe) in higher power applications.

Objective 4. Synthesis of digital engine, algorithms of digital controllers, design of hysteretic sliding mode feedback in VHDL. 
This Objective 4 has been achieved: All designed digital sliding mode controllers for HBLED drive systems, for either DC input or AC- Mains were programmed in VHDL. In fact, the Simplorer simulations performed in this project to verify the validity of the HBLED drive systems included this VHDL code in behavioral models of digital cores.

We have also designed, built and tested proof-of-concept prototype boards to drive HBLEDs with DC input. The board uploaded the VHDL code into an FPGA that implemented SynDiTec's pulsed current averaged controllers for a boost converter HBLED driving system. Experiments showed, for DC input, that SynDiTec's algorithms are simple to implement and are robustly stable.

\section{Phase I Project Activities for Research Findings and Results.}

We carried out our research for two power conversion topology approaches:

- Boost converter with the DC input.

- Buck-boost derived (including two-switch two-stage) topologies for offline applications.

The fundamentals of SynDiTec's Pulse Current Averaging Sliding Mode Control remain the same independent of topology. That is, the timing, state diagrams, stability theory, etc. are similar. Parameters and dynamic algorithms within the controller, however, must be different due to the power converters different dynamic models. By starting with an explanation of the boost converter with DC input, the approach for the off-line converters will be more easily understood:

\subsection{Boost Converter Research (DC Input Source)}

This subsection demonstrates how SynDiTec's developed digital controller with sliding mode scheme controls LED illumination systems for systems with DC voltage input.

As we will show, although the SynDiTec's control approach is digital, no external Analog to Digital (A/D) or Digital to Analog (D/A) converters are required for implementation. The Switched Mode Power Regulator used for this controller is a variable frequency boost DC-DC converter. The idea is to increase or decrease the duty cycle by discrete pulses in order to control the average current being delivered to a load. In summary, this portion of Phase I research analyzes how to control LED current when there is a DC input voltage source. Some results include:

- A new sliding mode pulsed current averaging LED driver IC has been designed, which does not require any external A/D or D/A converters.

- A DC-DC Boost converter has been used and a FPGA based digital controller has been experimentally implemented to control the duty cycle of the driver for a benchmark LED lighting system.

- The control scheme of the FPGA has been written in VHDL code.

- The system is robust to environmental changes, maintains high performance requirements and requires fewer passive components.

- The simulation results are applied to support both the theoretical and experimental analysis. 
- Block diagram and analytical design of an IC driver HB-LED system for DC voltage input source has been developed.

- A cost comparison between SynDiTec's digital/mixed signal architecture with existing technologies is made. Due to the reduced parts count and BOM of SynDiTec's approach, it is shown that cost of the LED drive system is approximately 40\%-60\% lower than comparable technology (and even significantly lower than other technologies).

\subsubsection{Design}

A simple representation of the LED drive system for DC input is shown in Fig. 1. Current going through the white LEDs are measured by a sense resistor. This $\mathrm{I}_{\text {load }}$ information is compared with a set point threshold $\mathrm{I}_{\text {set. }}$. The comparison is used by a digital compensator which calculates the pulse width for the switch. The digital controller uses proprietary SynDiTec pulsed current averaging sliding mode algorithms that are explained in the next subsection.

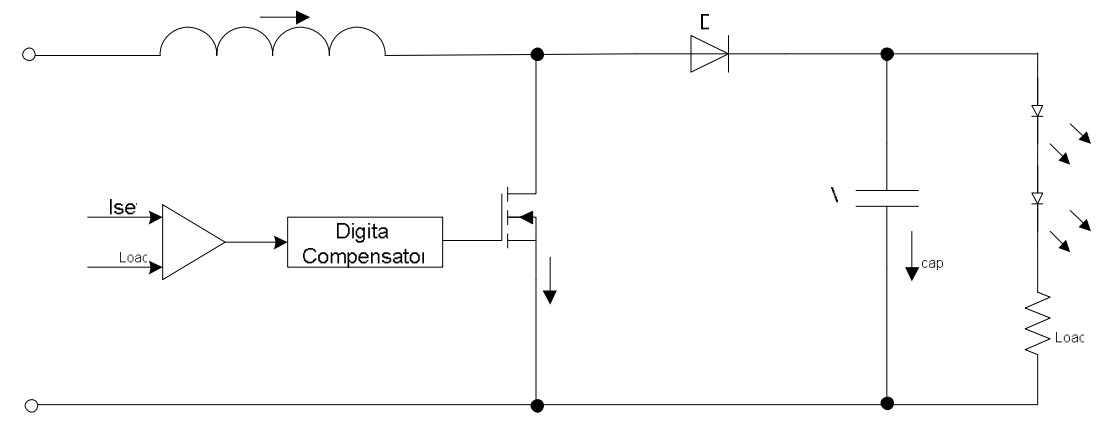

Fig. 1 Boost converter LED drive system studied in Phase I research.

\subsubsection{Digital Controller}

The digital controller implements a simple control method. The controller is an optimized digital core that uses a sliding control algorithm to determine the amount of power to transfer to the output. The developed algorithm uses discrete comparison of predicted output vs. sampled output. The digital core adjusts on time based on this comparison.

At the beginning of a cycle, the digital method turns on the switch and starts to count an oscillator clock. As shown in Fig. 2, when the counter value reaches a predefined $t_{\text {on }}$, it turns off the switch. This measures the switch on time. At the mean time, it also reads in the comparator result between $\mathrm{I}_{\mathrm{REF}}$ and $\mathrm{I}_{\mathrm{LED}}$. Depending on the comparator result, $\mathrm{t}_{\mathrm{on}}$ is adjusted by adding or subtracting a small amount $\Delta t$. This new $t_{\text {on }}$ is used in next cycle. Equation (1) is used to adjust ton when the comparator result is low or $\mathrm{I}_{\mathrm{LED}}<\mathrm{I}_{\mathrm{REF}}$.

$$
\begin{aligned}
& t_{\text {on }}(n)=t_{\text {on }}(n-1)+\Delta t(n) \\
& \Delta t(n)=\Delta t(n-1)+\delta
\end{aligned}
$$

where $\delta$ is a fixed clock cycle. 


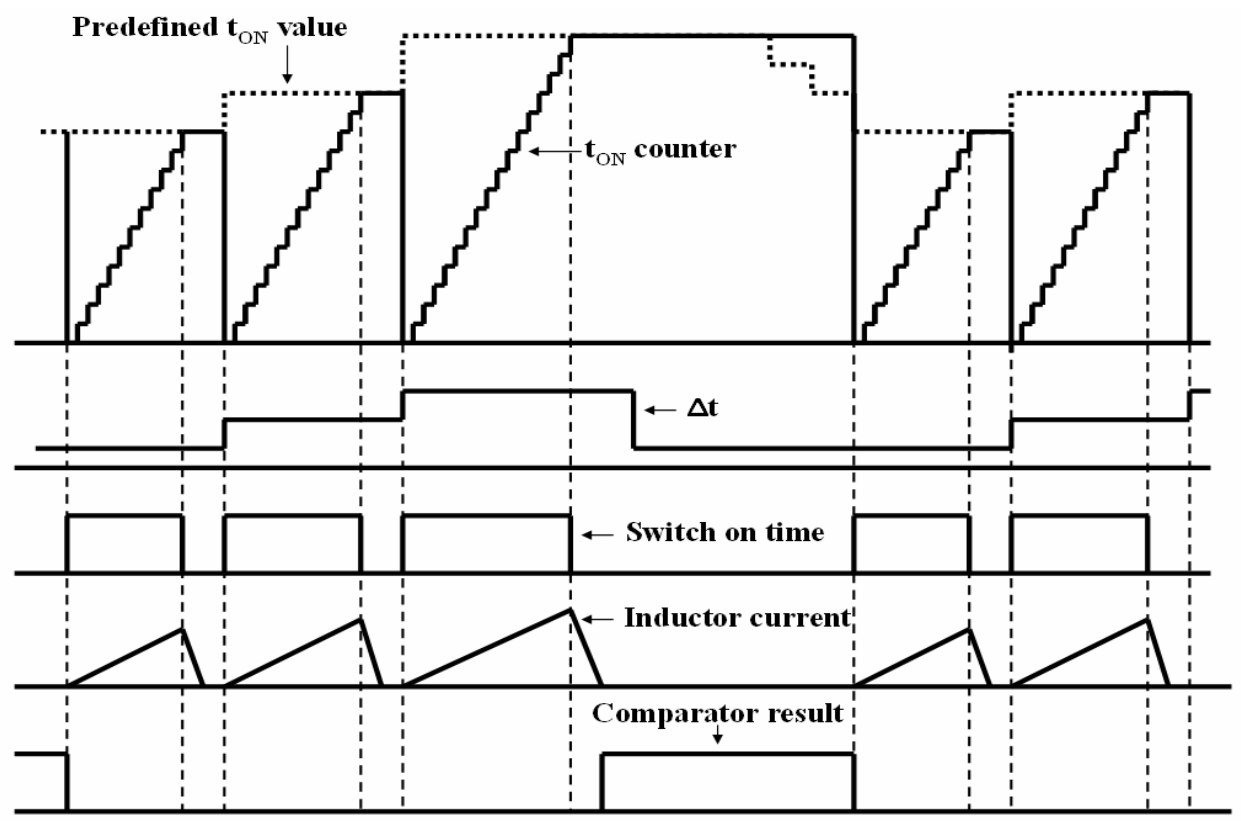

Fig. 2 Digital current mode control.

The comparator result is high when $\mathrm{I}_{\mathrm{LED}}>\mathrm{I}_{\mathrm{REF}}$. As shown in Fig. 2, $\Delta t$ maintains its initial value until the comparator is low again. Equation (3) is used to adjust $t_{\text {on }}$ when the comparator result is high. $t_{\text {on }}$ counter starts counting again when the comparator goes low.

$$
t_{o n}(n)=t_{o n}(n-1)-\delta
$$

As said earlier, the switch off time is fixed for normal operating conditions. But when the comparator result is high, the off time is longer than the fixed period and we call it a wait mode. In this mode $\mathrm{I}_{\mathrm{LED}}$ is greater than $\mathrm{I}_{\mathrm{REF}}$. That means enough power has already been delivered to the load. There is no necessity to turn on the switch again and deliver more power. Rather, the controller waits until the comparator goes low and starts its algorithm again. Thus in the toff wait mode, the boost converter switch remains open until the LED current decreases below the desired setpoint current.

The algorithm is explained further in the state machine shown in Fig. 3. This state machine is typical of the SynDiTec approach and is applicable to other power conversion topologies, including off-line converters. Notice at the bottom of the figure, there are three decisions to be made, each of which is based upon the outcome of a comparator (and not an A/D converter). Either the LED current is: (1) greater than $I_{R E F}$, (2) equals $\mathrm{I}_{\mathrm{REF}}$ (within some small tolerance) or (3) is less than $\mathrm{I}_{\mathrm{REF}}$. In each of these cases, the IC controller makes a decision, in digital, how to update the controller algorithm with the goal to make $\mathrm{I}_{\mathrm{LED}}-\mathrm{I}_{\mathrm{REF}}$ approximately equal to 0 . The actual update algorithm within the digital core can be optimized by software and depends on the topology used and the application.

It is important to remark that this algorithm is unique in the sense that it does not require external A/D converter in order to run. Instead, it should be possible to measure inductor 
current through a standard sense resistor and send it directly to the driver IC. The interface between the sensed signals (integrated) and the digital logic is through a simple comparator. Thus, the controller is digital, yet it relies on comparators that are analog. Hence, the approach is a mixed-signal (analog + digital) control architecture.

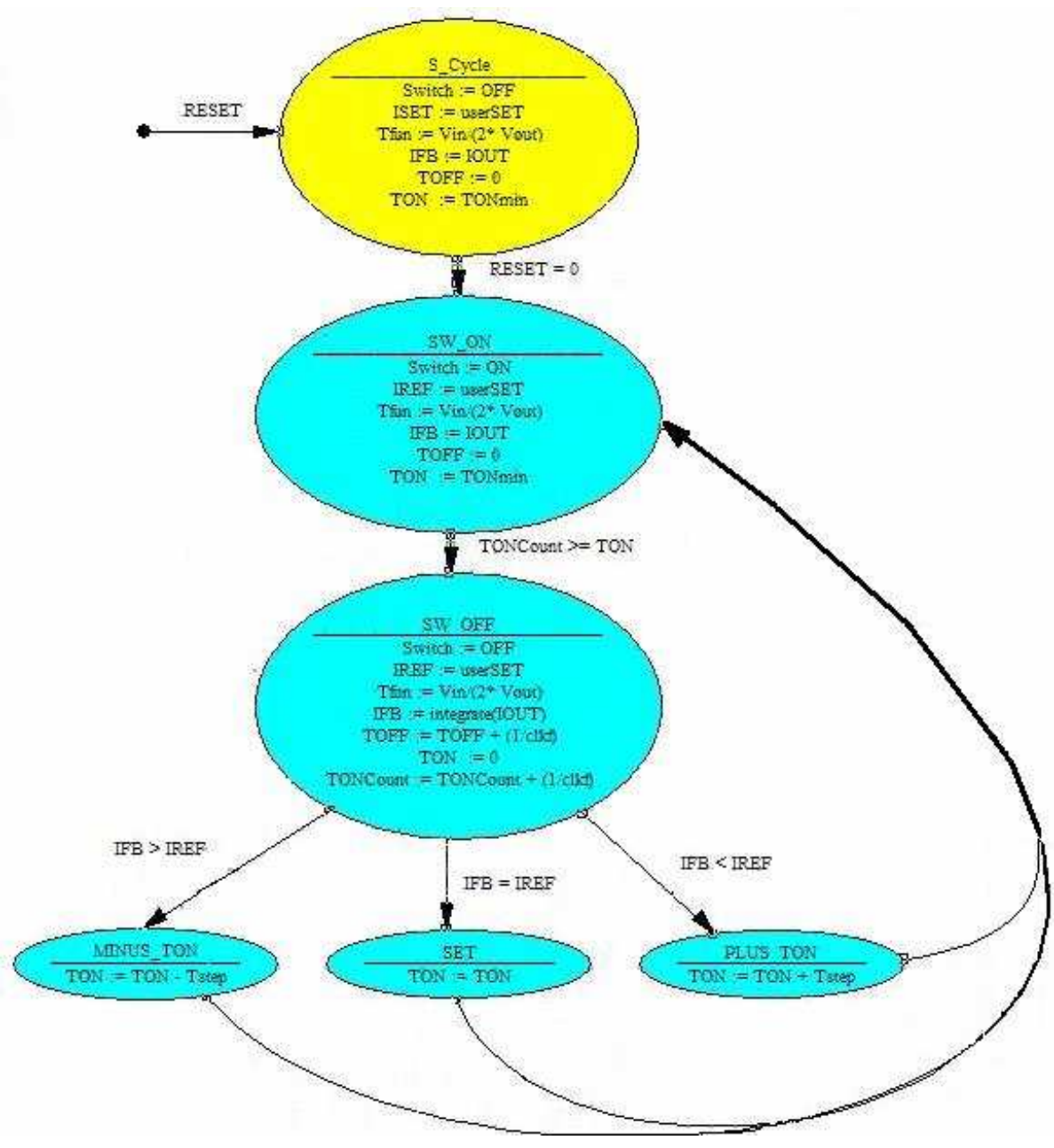

Fig. 3 State Machine.

Fig 4. illustrates the block diagram model that qualitatively explains the new control approach. The LED current is compared to a reference value. If the reference value is above the actual LED current, then the on-time of the converter is increased. However, the rate it can increase is limited cycle-by-cycle. This is modeled in Fig 4 by a "rate limiter." Simulations and analysis show that this rate limiter has a stabilizing effect if the boost converter operates in Discontinuous Conduction Mode (which it is designed to do). In fact, conventional hysteretic control algorithm will not work properly unless the SynDiTec specialized "rate limiter" is added. 


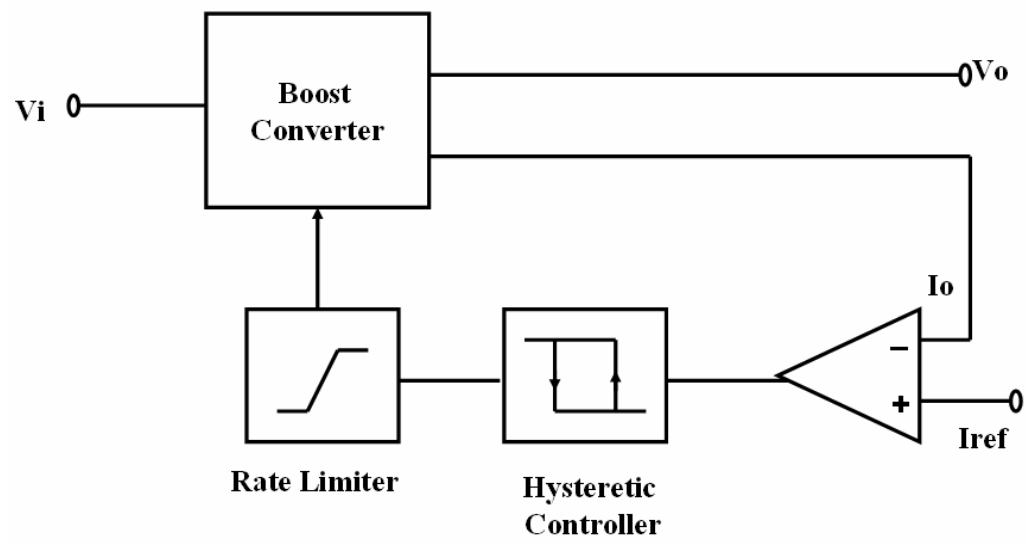

Fig. 4 The SynDiTec pulse current averaged controller has been behaviorally modeled by a hysteretic controller with a special type of rate limitation feedback.

Figures 4 and 5 illustrate the fact that the SynDiTec controller with unique rate limiter is able to stabilize and control the LED current in the boost converter configuration. In Fig. 5 , the SynDiTec pulse current average controller is utilized, and the figure illustrates that the LED current stabilizes to approximately 20mA, while the boost inductor current remains in DCM with peak value of $120 \mathrm{~mA}$. On the other hand, if traditional hysteretic control is used without the SynDiTec rate limiter, Fig. 6. illustrates the controller does not work. That is, although the LED current stabilizes around $20 \mathrm{~mA}$, the inductor current never reaches steady state, and eventually ramps to theoretically infinity (shown in the illustration during transient to be 175A). Thus, the SynDiTec controller appears to maintain the simplicity of hysteretic control, but because of the unique algorithm, is applicable to HB LED systems that previously could not be directly applied to with traditional hysteretic control.
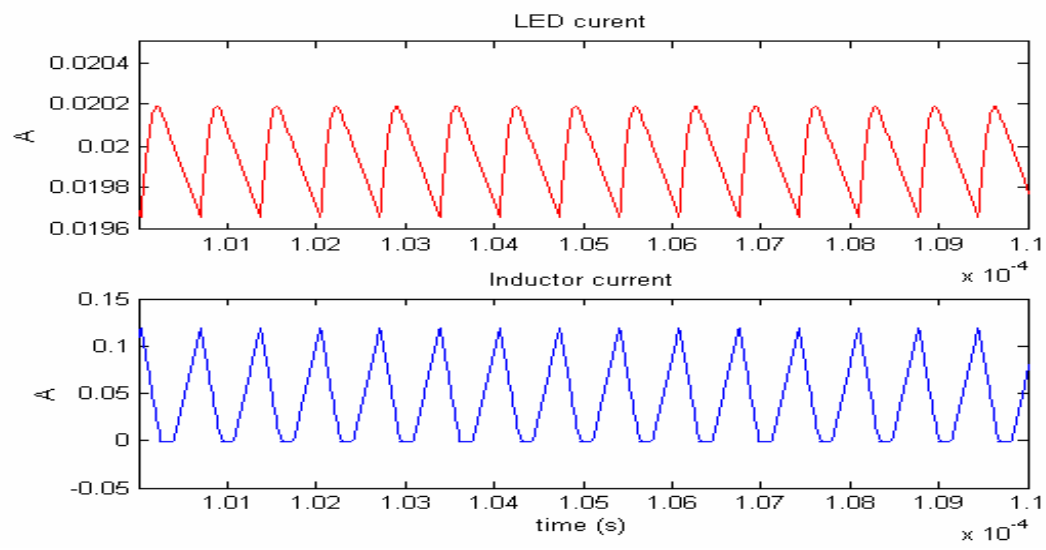

Fig. 5. The SynDiTec pulsed current averaged hysteretic controller stabilizes the LED current to $20 \mathrm{~mA}$, while maintaining safe inductor current values. 

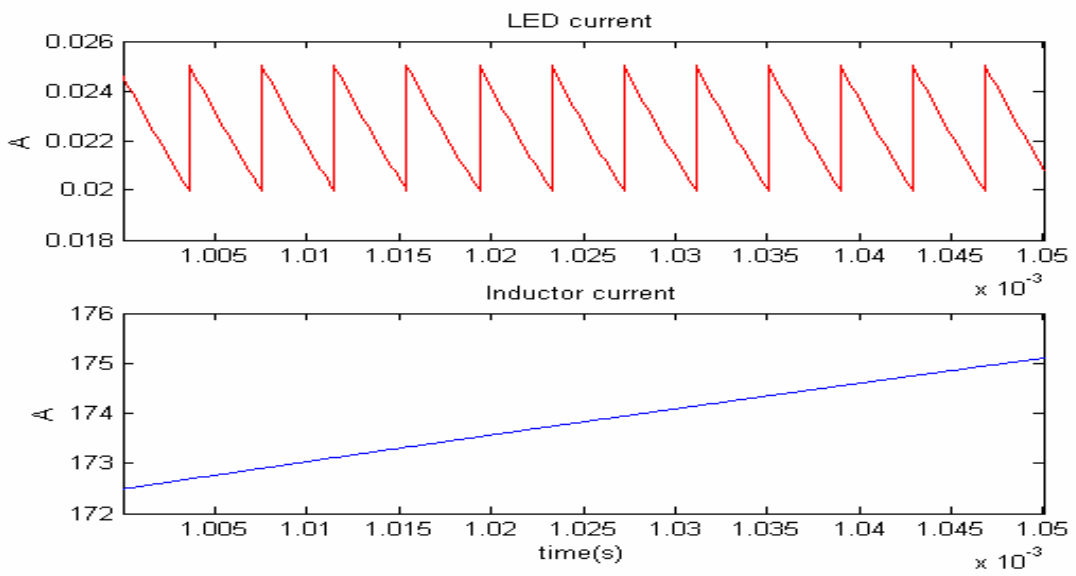

Fig 6. Traditional hysteretic control is not practical with a boost converter driving LEDs. Although the LED current stabilizes, the inductor current ramps to unsafe values.

\subsubsection{Block Diagram of SynDiTec Boost Converter HB-LED drive system}

The previous subsection gave an overview of the control algorithm IC and how it is possible to use comparators instead of $\mathrm{A} / \mathrm{D}$ or $\mathrm{D} / \mathrm{A}$ converters. Based on this approach, a block diagram of a mixed signal IC is shown in Fig. 7. Notice that the comparators, digital core, primary switch and all external components for overvoltage and overcurrent protection are within the IC. The IC definition is targeted to have 5 pins in a SOT23-5L package.

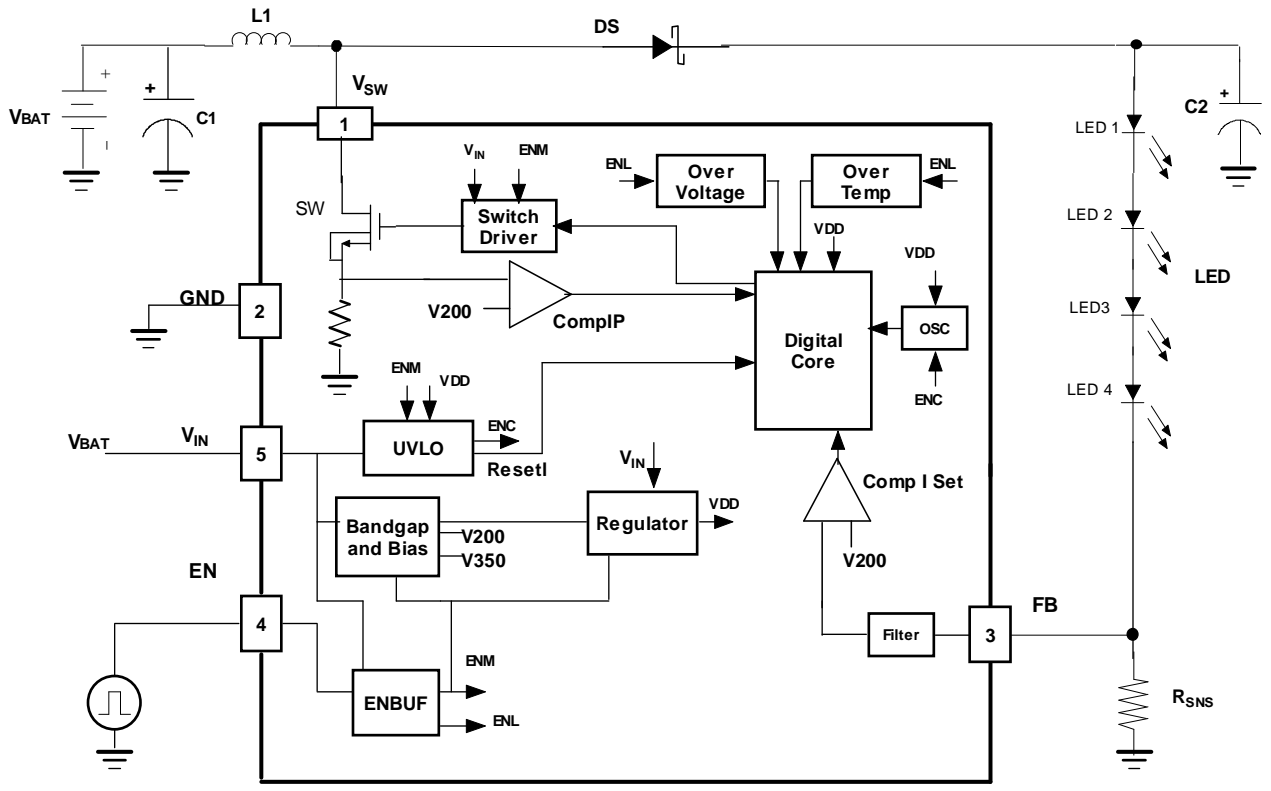

Fig.7 Sliding mode controller IC block diagram. 


\subsubsection{Behavior Simulation}

In order to validate the control method from previous section, a behavior simulation platform has been constructed, using software Simplorer from Ansoft corporation. Fig.8 shows a schematic within Simplorer software. Simplorer is capable of simulating the entire boost converter system. A voltage source $\mathrm{V}_{\text {bat }}$ models a battery, $\mathrm{L}_{1}$ models the boost inductor, $\mathrm{D}_{1}$ models the flyback diode, LED1 to LED4 model the white LED load and $\mathrm{R}_{\text {set }}$ is the sensing resistor. The solid lined box encloses components to be made into a silicon integrated circuit (IC SD0). Power switch S1 is turned on and off to store and fly the energy within the inductor to output. Comparator CompOVP senses over voltage. CompIP senses peak current of switch S1 during turn on. CompVinmin senses minimum input voltage for enabling the IC. CompISET compares a set threshold against the output current through external resistor $\mathrm{R}_{\text {set }}$. CompSHORT detects output short circuit condition. An oscillator of $12.5 \mathrm{~ns}$ cycle time is also incorporated.

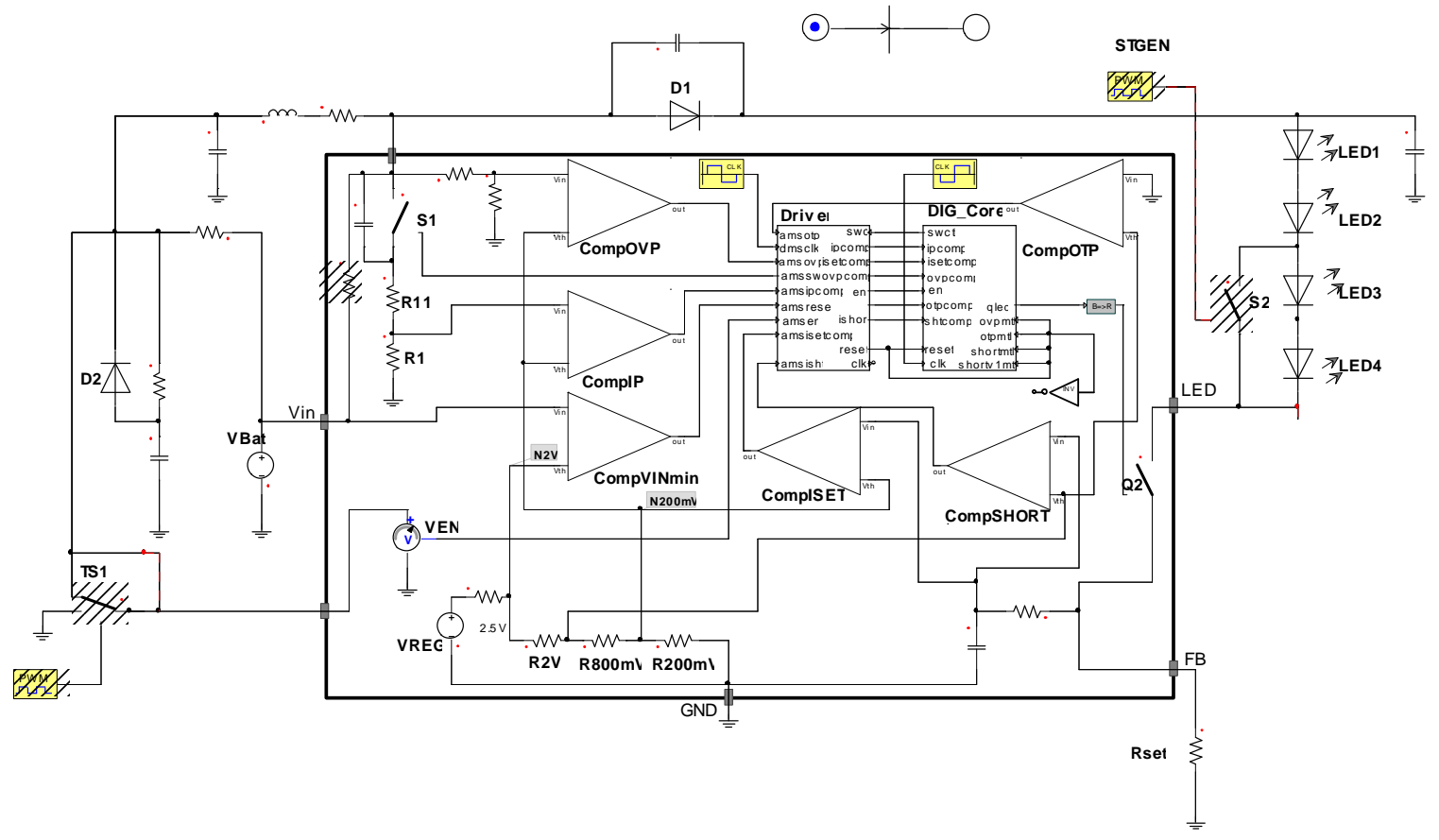

Fig. 8. A Simplorer platform to validate the control method.

All above comparator outputs are fed into the digital core where the control method is implemented. The Sd0 Digital (also called boost digital), provides the primary control of the IC. It is programmed to run the previously described pulsed current averaged sliding mode control algorithm. This type of simulation represents a fairly accurate behavioral approach of the entire LED drive system because it provides a mixed signal simulation environment that allows for comparators and digital algorithms to be used in the same simulation environment.

Using the Simplorer simulator, Fig. 9 illustrates some typical waveforms. 


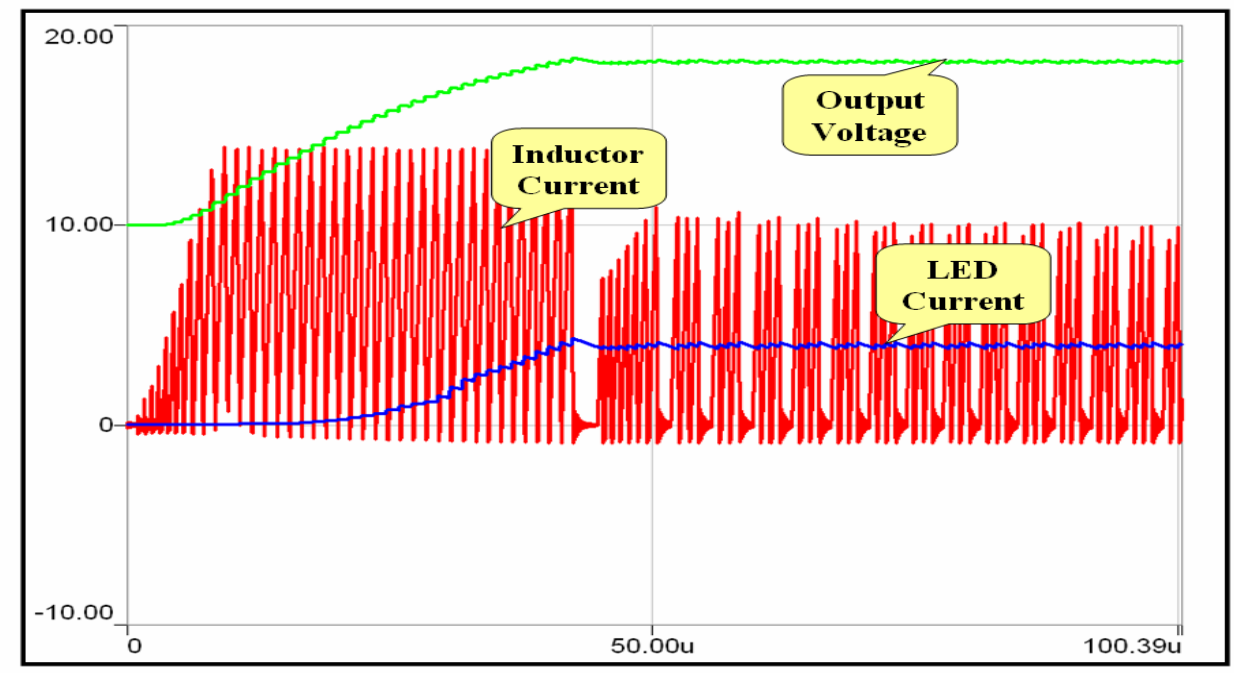

Fig. 9. Simulation of a start up of a the boost converter.

Notice in Fig. 9 that, as designed, the inductor current operates in discontinuous conduction mode as it enters steady state. The LED current approaches a (nearly) constant 20mA, while the output voltage across the string of LEDs goes to steady state value of around $18 \mathrm{~V}$. There is no noticeable subharmonic oscillation in the LED current or ripple on the LED current. Essentially, it has been regulated to the desired value. Startup is also shown in the Fig. 9 and is implemented within the IC, using an algorithm programmed onto the digital core.

\subsubsection{FPGA Prototype to Verify Phase I Results}

Although not one of the promised deliverables in the Phase I proposal, SynDiTec has actually designed, built and tested a working prototype that implements the SynDiTec digital core on an FPGA board. The board attempts to implement the diagram in Fig. 7, although the comparators and other analog components illustrated in the figure are separate external components on the board. (This is why the board is large $\left(5^{\prime \prime} \times 3^{\prime \prime}\right)$, and does not reflect in any way the size of the IC.)

Fig. 10 shows the prototype of the LED driver with digital controller. The FPGA is running the sliding mode pulsed current averaging IC Drivers, following the state machine in Fig. 7 and equations (1)-(3). The board can drive 8 LEDs maximum and the maximum current should be no more than $40 \mathrm{~mA}$. One potentiometer is used to SET the output current : $\mathrm{I}_{\mathrm{SET}}=0.200 / \mathrm{R}$. The nominal operating range of the input voltage is 2.5 7 Volts. The several main components used in the prototype other than passive components are shown in Table I.

Table I LED Driver Prototype

\begin{tabular}{|c|c|c|}
\hline Description & PartType/Number & Footprint \\
\hline Xilinx XL95288-6 & F-QFP20X20-G1471 & XC95288XL-TQ144 \\
\hline $\begin{array}{c}\text { 60V,2A MOSFET, } \\
\text { Siloconix }\end{array}$ & SI2308DS & SOT-23N \\
\hline Micrel MosFET Driver & MIC4416 & SOT143-2 \\
\hline
\end{tabular}




\begin{tabular}{|c|c|c|}
\hline Schimdt Buffer & SN74LVC1G17 & DBV-SOT23-5 \\
\hline 4ns Comparators & AD8612 & TSSOP14 \\
\hline
\end{tabular}

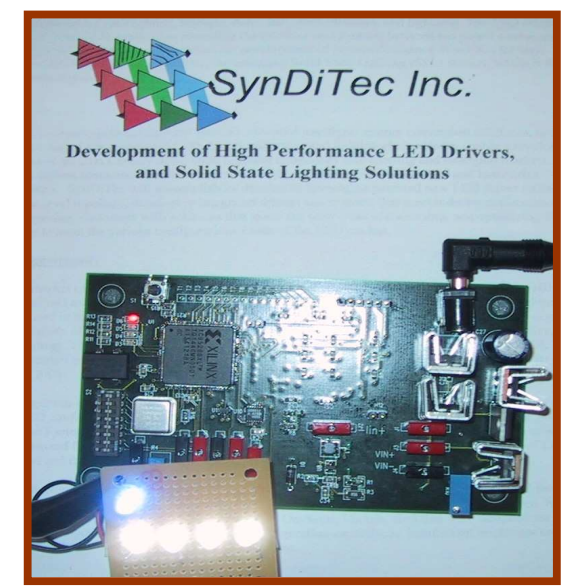

Fig. 10. Prototype of the LED drive

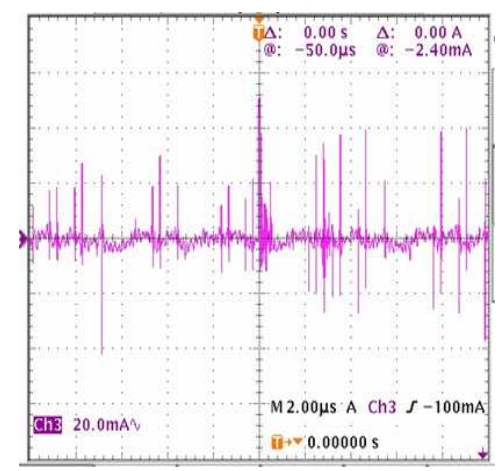

Fig. 11. Experimental results of the LED current.

Experimental waveforms from the prototype board are shown in Fig. 11. The results match the simulations and further indicate that the digital core approach works to drive HB -LEDs.

\subsubsection{Global Stability and Robustness of the SynDiTec Control Algorithms}

Phase I research spent great effort to theoretically prove that SynDiTec control algorithms were globally asymptotically stable.

Qualitatively, the theoretical proofs include the following conclusions:

1. SynDiTec's controllers are globally asymptotically stable when applied to any boost or buck-boost derived topology with inductor current in discontinuous conduction mode. Specifically, the LED current will always approach a small periodic orbit whose average value is equal to the desired LED current. The results are valid for DC input voltage or for off-line buck-boost converters. SynDiTec's controllers have perfect regulation with zero steady state error. The LED current always approaches its desired setpoint current. This is true for both DC input and off-line systems with AC-mains.

2. SynDiTec's control algorithms are robust to load, line and inductor current disturbances. Differential geometric arguments show that such disturbances do not affect steady state LED current regulation. That is, the LED current regulates to the desired setpoint value for DC or AC-mains input systems. Simulations verify all theoretical analysis.

3. Global asymptotic stability and perfect regulation is independent of LED diode parameters. The value of the LED on-resistance, $\mathrm{R}_{\mathrm{D}}$, or its on-voltage, $\mathrm{V}_{\mathrm{DO}}$, does not influence steady state error or stability. They only affect the dynamic speed of response. This implies that the algorithms will work well with variety of HBLEDs from different manufacturers. Simulations verify all theoretical analysis. 
All these above statements are fully supported by rigorous theoretical analysis that utilizes differential geometry and comparison principles for stability analysis. The claims are also supported fully by dozens of numerical experiments in Simplorer and MATLAB as well. We remark that the claims for robustness (3 and 4) are typical features of general sliding mode controllers and were expected. This robustness is a clear advantage to SynDiTec's approach over state-of-the-art linear controllers for LED driving.

Typical simulations that demonstrate global stability and setpoint regulation are given in Fig. 12 and Fig.13. Figure 12 shows how the orbit is oscillating around $\mathrm{I}_{\mathrm{REF}}$ in a typical application. Notice that there are three cycles of increasing $t_{\text {on }}$, and then the controller enters t_off Wait Mode. As the controller increases $t_{\text {on }}$, the LED current begins to rise (notice how its average value is rising). When the average LED current reaches above $\mathrm{I}_{\mathrm{REF}}$ the switch closes and the average LED current drops. Hence, the LED current hovers around this globally asymptotically stable periodic orbit.

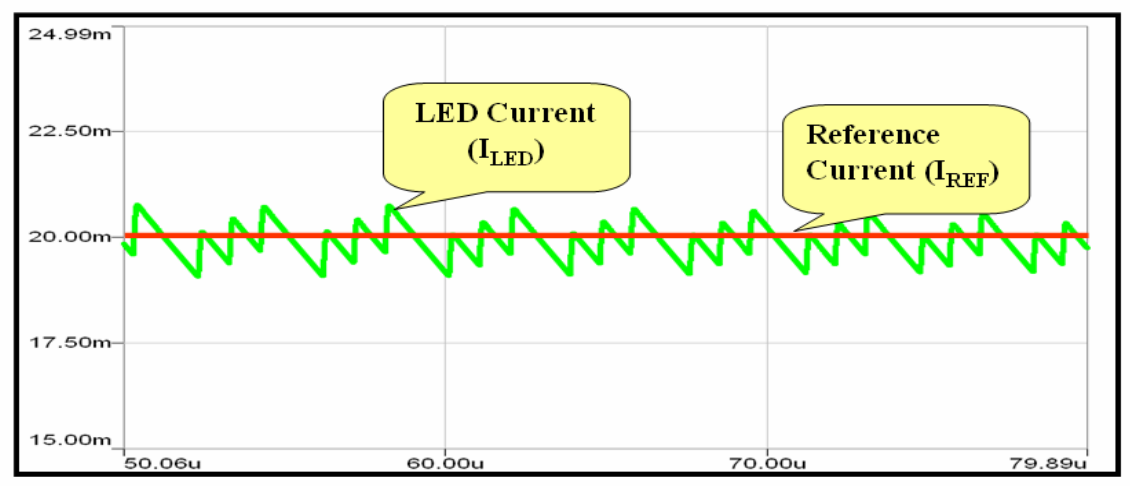

Fig. $12 \mathrm{LED}$ and reference current vs. time.

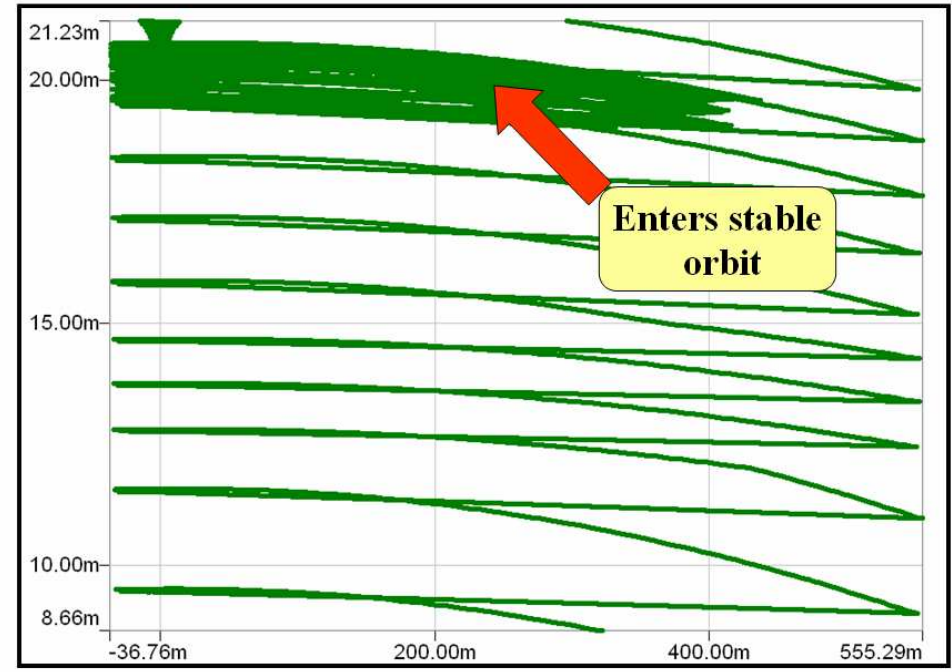

Fig 13. Phase plane plot $\left(I_{L E D} V S I_{L}\right)$.

Fig. 13 shows the phase plane plot of LED current vs. inductor current. The phase plane plot shows how the states reach the desired "sliding surface" and after stays in the small neighborhood of the (globally) asymptotically stable periodic orbit. Since the frequency of orbit is so high, for all practical purposes, the LED current can be considered to be 
constant and equal to the desired setpoint, to the human eye, the LED's appear to have constant illuminations.

Table II

Cost comparison of Sd1 and HV9906

\begin{tabular}{|l|l|l|}
\hline Components of the cost & SynDiTec (Fig. 11) & HV9906 \\
\hline $\begin{array}{l}\text { Total DigiK ey supply cost } \\
\text { ( IC excluded) }\end{array}$ & $\mathbf{3 . 8 1}$ & $\mathbf{7 . 7 9}$ \\
\hline Volume cost ( IC excluded) & 1.27 & $\mathbf{2 . 6 0}$ \\
\hline IC cost & $\mathbf{0 . 8 0}$ & $\mathbf{0 . 8 0}$ \\
\hline Manufacturing cost & $\mathbf{0 . 2 0}$ & $\mathbf{0 . 2 0}$ \\
\hline Cost of the driver & $\mathbf{2 . 2 7}$ & $\mathbf{3 . 6 0}$ \\
\hline Price of the driver & 4.54 & $\mathbf{7 . 2 0}$ \\
\hline \$/W & $\mathbf{0 . 2 2}$ & $\mathbf{0 . 3 6}$ \\
\hline Part count & 21 & 38 \\
\hline
\end{tabular}

\subsection{Off-line LED Drivers}

This subsection demonstrates how SynDiTec's developed digital controller with sliding mode scheme controls LED illumination systems for off-line power converters, i.e. when the input source is taken from the AC-mains.

Just as in the previous section for DC input, SynDiTec's digital control approach does not utilize $\mathrm{A} / \mathrm{D}$ or $\mathrm{D} / \mathrm{A}$ converters in its implementation, hence, reducing external parts count and BOM.

In summary, this portion of Phase I research for off-line converters claims the following research results:

- A new sliding mode pulsed current averaging LED driver IC has been implemented, which does not require any external A/D or D/A converters. The driver is suitable for various buck-boost derived topologies.

- Significant shortcomings of existing off-line LED drive systems were newly discovered. Specifically, LED off-line drive systems presently must use electrolytic capacitors for filtering. Electrolytic capacitors have lifetime expectancy significantly less than LEDs.

- A specialized two-stage converter LED drive system is designed that requires lower value output filter capacitance. Therefore, non-electrolytic capacitors can be used, thus giving the new LED drive system longer lifespan. (Some capacitors have lifespan above 100khrs, as required by LEDs. Phase II research will investigate the types of capacitors that should be used in this converter.)

- SynDiTec's pulsed current averaging approach is demonstrated in theory to have unity power factor (see Appendix 4 for proof).

- Simulation results in Simplorer support the theoretical analysis of near unity power factor and stability of SynDiTec's pulsed current averaged digital controllers. 
- Block diagram and analytical design of an IC driver HB-LED systems for AC voltage input source.

\subsubsection{Topologies and Component Comparisons of SynDiTec's Two Approaches}

For off-line LED Drivers we considered applications of two topologies, capable to deliver power factor correction: single stage buck-boost converter and single switch two stage buck-boost-buck converters (see Fig.14 and 15).

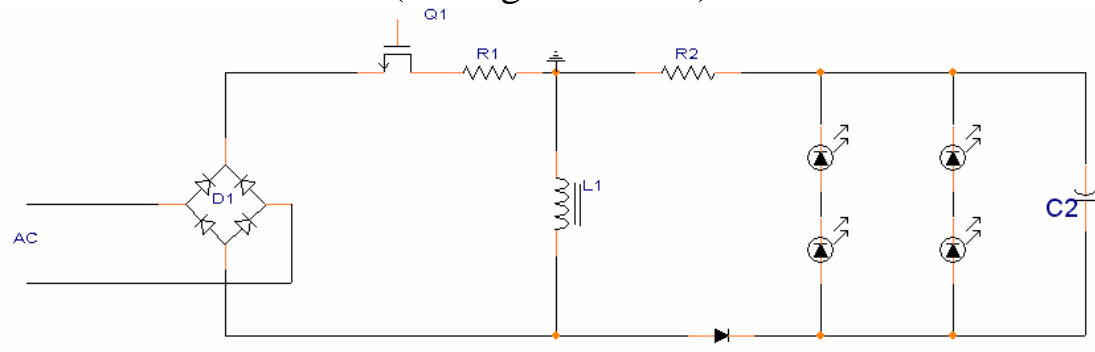

Fig 14. Buck-Boost converter.

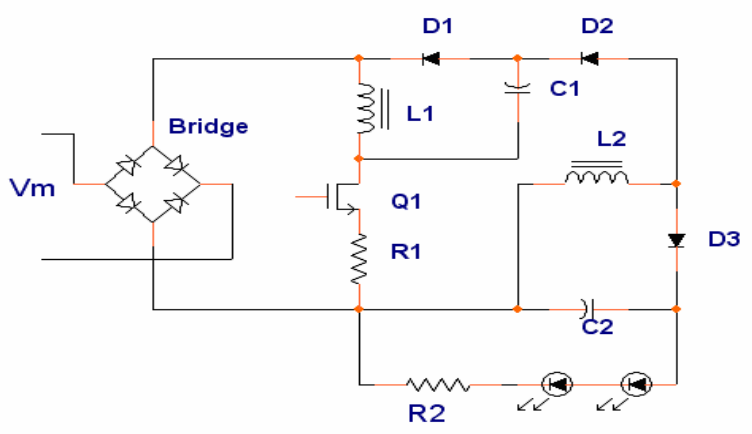

Fig. 15. Proprietary Single Switch Two Stage converter.

Detailed analysis of off-line converters is also discussed later in this report. In particular, Phase I research also focused on the optimization and design of off-line driver ICs as in Fig. 14 and Fig. 15. However, we have done substantial analysis and simulation of the two topologies. Some interesting comparisons are presented in Table III, below.

Table III. Buck-Boost and Two Stage Converters

\begin{tabular}{|l|c|c|c|}
\hline \multicolumn{1}{|c|}{ Parameters } & References, units & Buck-boost & Two Stage \\
\hline Output voltage & Vo, V & 16 & 16 \\
\hline Output current & Io, A & 1 & 1 \\
\hline Output power & Po, W & 16 & 16 \\
\hline Efficiency & $\eta$ & 0.9 & 0.9 \\
\hline $\begin{array}{l}\text { Input voltage, } \\
\text { amplitude }\end{array}$ & Vm,, & 120 & 120 \\
\hline Input power & Pin, W & 17.8 & 17.8 \\
\hline $\begin{array}{l}\text { Input current, } \\
\text { amplitude }\end{array}$ & Im, mA & 297 & 297 \\
\hline Switching frequency & $\mathrm{kHz}$ & 200 & 200 \\
\hline On-time & Ton, us & 0.59 & 1.34 \\
\hline Inductance & $\mathrm{L}, \mathrm{uH}$ & 14.1 & \\
\hline
\end{tabular}




\begin{tabular}{|c|c|c|c|}
\hline Inductance & $L_{2}, \mathrm{uH}$ & & 21.5 \\
\hline Inductance & $L_{1}, \mathrm{uH}$ & & 72.6 \\
\hline Peak current & $I_{p 1}, \mathrm{~A}$ & 5.02 & 2.21 \\
\hline Peak current & $I_{p}, \mathrm{~A}$ & & 2.73 \\
\hline Inductors size $\propto$ & $\overline{L I^{2}, \boldsymbol{\mu} H \cdot A^{2}}$ & 356 & 516 \\
\hline $\begin{array}{l}\text { Voltage ripple, } \\
\text { p-p, second } \\
\text { harmonic }\end{array}$ & $\Delta V_{c}, \mathrm{~V}$ & 0.8 & 0.8 \\
\hline Output capacitor & $\mathrm{C}, \mathrm{uF}$ & 2140 & 244 \\
\hline $\begin{array}{l}\text { RMS current of the } \\
\text { output capacitor }\end{array}$ & Irms, A & 1.91 & 1.68 \\
\hline Filter capacitor & $C_{1}, \mathrm{uF}$ & & 195 \\
\hline $\begin{array}{l}\text { RMS current of filter } \\
\text { capacitor }\end{array}$ & Irms, A & & 1.3 \\
\hline Capacitors size $\propto$ & $C V^{2} I_{r m s}, \mu F V^{2} A$ & $1.05 \cdot 10^{6}$ & $1.25 \cdot 10^{6}$ \\
\hline EMI filter size $\propto$ & $I_{p}^{2}, A^{2}$ & 25.2 & 4.88 \\
\hline
\end{tabular}

We see that the Two Stage Converter has an advantage in much smaller RMS currents, which leads to the significantly smaller EMI filter. Probably Buck-Boost will serve better smaller power drivers, perhaps up to $10-15 \mathrm{~W}$. Anything above that may be better powered by a two stage converter.

\section{Comments on (Electrolytic) Capacitor Filter}

Notice in Table I that the typical buck-boost converter requires output capacitors that are approximately 10 times the size of the Two Stage Converter. For such a large filter, electrolytic capacitance must be used. The requirement of this size is due to the inductor current ripple that is inherent to the buck-boost.

An electrolytic capacitor is a type of capacitor with a larger capacitance per unit volume, making them valuable in relatively high-current and low-frequency electrical circuits. Electrolytic capacitors are constructed from two conducting foils, one of which is coated with an insulating oxide layer, and a paper spacer soaked in electrolyte. The foil insulated by the oxide layer is the anode while the liquid electrolyte and the second foil act as cathode. This stack is then rolled up, fitted with pin connectors and placed in a cylindrical aluminum casing. The electrolyte is usually boric acid or sodium borate in water with some sugars or ethylene glycol added to retard evaporation. Many factors like electrolyte type, quality of the sealing system, operating temperature etc. affect the life of the capacitor. Over a long time, the liquid can dry out, causing the capacitor to fail. The operational lifetime of an electrolytic capacitor is based mainly on the rate of electrolyte diffusion during operation. If the electrolytic capacitors are not properly sealed, the 
electrolyte in these capacitors eventually evaporates causing increased ESR which causes increased heating, sometimes the capacitors explode.

High quality electrolytic capacitors have a service life of about 30,000 hours at $85^{\circ} \mathrm{C}$. Very cheap small electrolytic capacitors have a service life of 1000 hours at $85^{\circ} \mathrm{C}$. HBLEDs are expected to last between 50,000 to 100,000 hours. But the electrolytic capacitors used in the LED drivers can not last more than 30,000 hours (best case). So it is impossible to use electrolytic capacitors in LED drivers for HB-LEDs for long term use unless new ideas can be invented. This is the reason that the two-stage off-line converter seems attractive. For example, the low valued capacitance required for its filters indicates that non-electrolytic capacitors can be utilized. For example, film capacitors, ceramic capacitors, and tantalum capacitors have substantially longer lifetime than electrolytics, and all can be found in the $200 \mu \mathrm{F}$ range as required. Tantalum capacitors are much costlier, and therefore should not be used in low cost drivers.

\subsubsection{SynDiTec Universal Approach and Block Diagrams for Off-Line LED Drive Systems}

The outlined below digital core (SDT core) uses a digital control algorithm that is designed to universally control the single switch types of AC-DC current source converters that are used to drive a string of $\mathrm{N}$ number of LEDs with a constant "user adjustable" current, including the two converters described above.

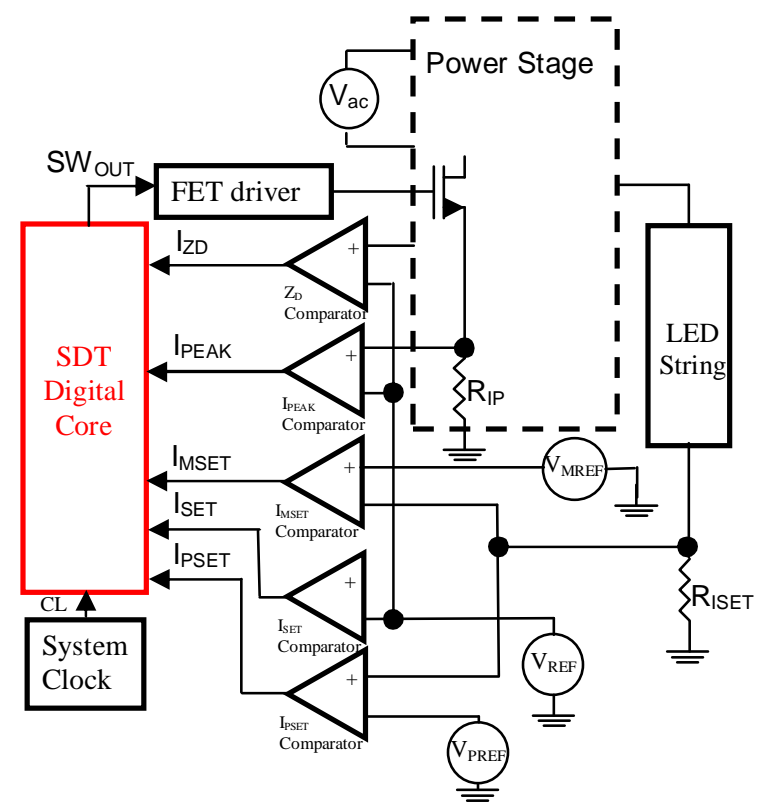

Fig. 16 Model of an AC-DC current source.

As shown in Fig. 16. the basic connections to the SDT digital core are defined as:

$\mathrm{I}_{\mathrm{ZD}} \Rightarrow$ Digital input that signals to the logic when there is current in the primary inductor.

When the voltage across the primary inductor is greater than $\mathrm{V}_{\mathrm{REF}}$, the $\mathrm{I}_{\mathrm{ZD}}$ comparator trips. 
$I_{\text {PEAK }}=>$ Digital input that signals to the logic when maximum allowable switch current is reached.

When the voltage across $R_{I P}$ is greater than $V_{R E F}$, the $I_{\text {PEAK }}$ comparator trips.

$\mathrm{I}_{\text {MSET }}=>$ Digital input that signals to the logic when the output current is at a minimum from the desired set current. This is the lower part of a window comparator structure.

When the voltage across $R_{\text {ISET }}$ is less than $V_{\text {MREF, the }} I_{M S E T}$ comparator trips.

$\mathrm{I}_{\mathrm{SET}} \Rightarrow>$ Digital input that signals to the logic when the output current is at the desired value.

When the voltage across $R_{\text {ISET }}$ is greater than $V_{\text {REF, the }} I_{S E T}$ comparator trips.

$\mathrm{I}_{\mathrm{PSET}}=>$ Digital input that signals to the logic when the output current is at a minimum from the desired set current. This is the upper part of a window comparator structure.

When the voltage across $R_{I S E T}$ is greater than $V_{\text {PREF, the }}$ IPSET comparator trips.

$\mathrm{SW}_{\text {out }}=>$ Digital output that, with a FET driver controls, the switching of the converter.

CLK $=>$ Digital input, system clock.

A system block diagram of the non-isolated buck-boost converter is given below, where the SD1 represents SynDiTec's IC.

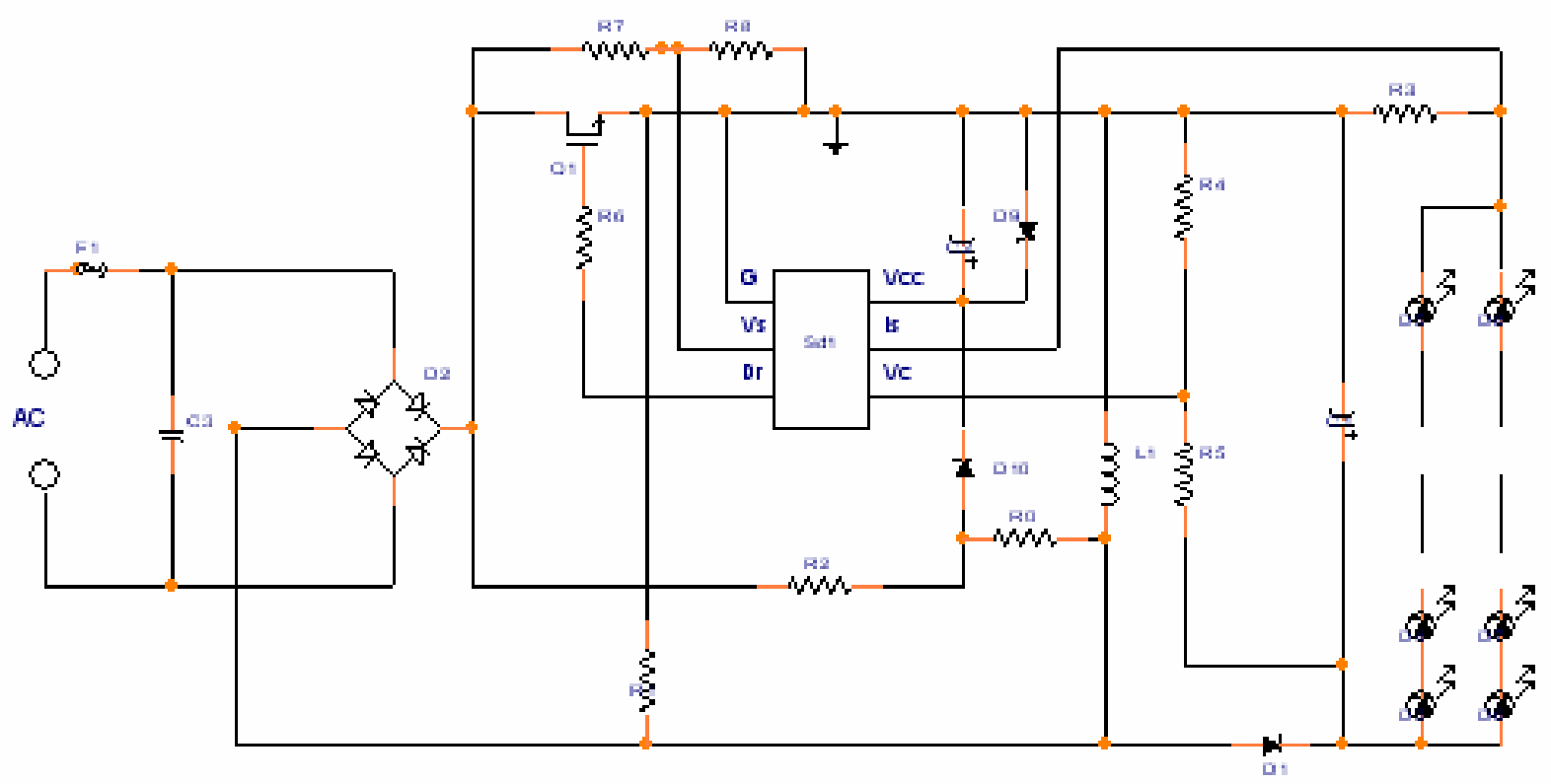

Figure 17. Block diagram of buck-boost converter with AC-mains.

\subsubsection{The Algorithm}

Similar to before for DC input, the SynDiTec (SDT) digital core algorithm consists of three state machines. The state machines operate in synchronization, combined they provide the control elements, implementing Pulse Current Averaging Sliding Mode 
Control, that results in output current regulation with input AC current, shaped to have a sinusoidal form.

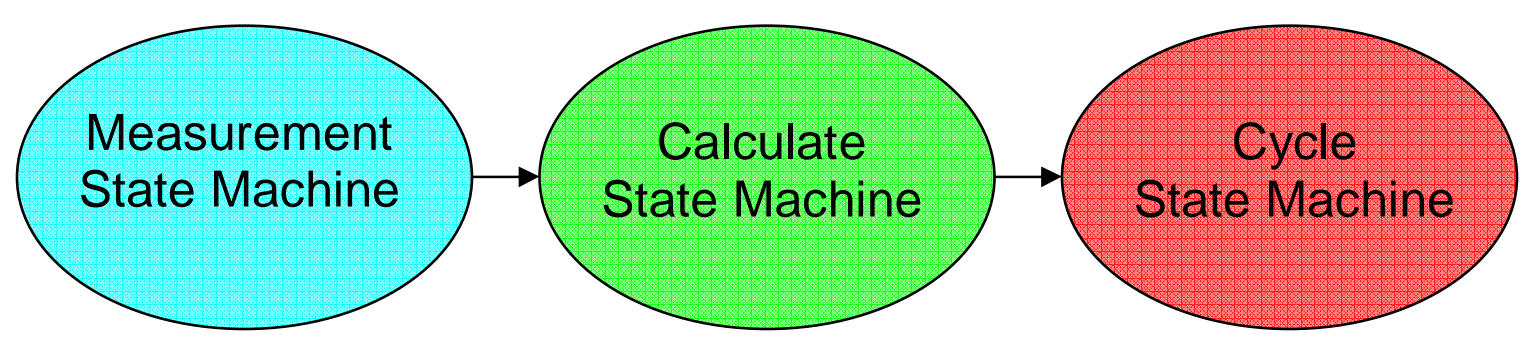

Fig.18 Three state machines.

The SDT digital core uses the following variables:

$\mathrm{ON}_{\mathrm{CNT}}=$ This register stores the number of system clocks that the digital core will keep the switch transistor closed $\left(\mathrm{SW}_{\text {out }}=1\right)$.

$\mathrm{OFF}_{\mathrm{CNT}}=$ This register stores the number of system clocks that the digital core will keep the switch transistor open $\left(\mathrm{SW}_{\text {out }}=0\right)$.

$R S T_{C N T}=$ This register stores the reset time $\left(\mathrm{t}_{\mathrm{r} 0}\right)$ in number of systems clocks.

$\mathrm{ON}_{\mathrm{CALC}}=$ This register stores the calculated next $\left(\mathrm{t}_{\mathrm{on} 1}\right)$ in number of systems clocks.

$\mathrm{OB}_{\mathrm{CNT}}=$ This register stores the number of switching cycles (n) that the output dc current $\left(\mathrm{I}_{0}\right)$ is outside of the comparator window.

$I N_{C N T}=$ This register stores the number of switching cycles (n) that the output dc current $\left(\mathrm{I}_{0}\right)$ is inside of the comparator window.

$\mathrm{N}_{\mathrm{CNT}}=$ This counter counts the number of cycles from reset (or power up) until start up ends i.e. the convert achieves it's set point $\mathrm{I}_{0}$ the counter will count to a maximum value of 64 .

\subsubsection{Simulation Results}

The integrated digital core and Buck - Boost converter Fig.18 and two stage converter Fig.19 driving NeoPac Light engine was simulated on SIMPLORER. We present only typical results in this sub section.

We previously described our approach for IC behavior simulation. In order to validate the control method for the IC, a similar behavior simulation platform will be constructed using software Simplorer from Ansoft Corporation Simplorer is capable of simulating the entire system - digital controller and power stage ( See Fig.19) 


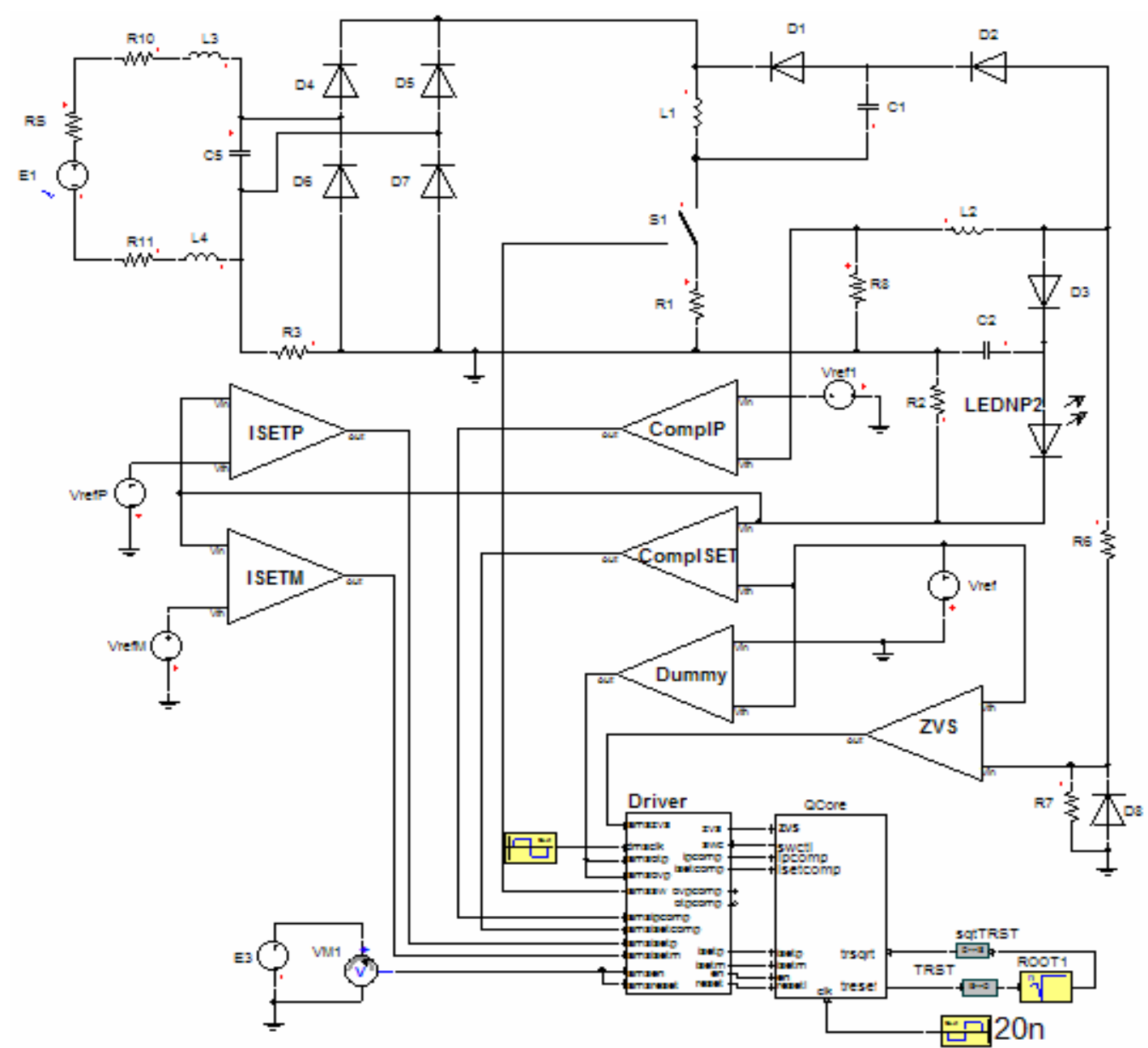

Fig. 19. A Simplorer platform to validate the control method of two stage converter.

All analog block outputs are fed into the digital core where the control method is implemented in VHDL language. The control method is then subjected to tens of test cases which run across typical and corner application operation conditions.

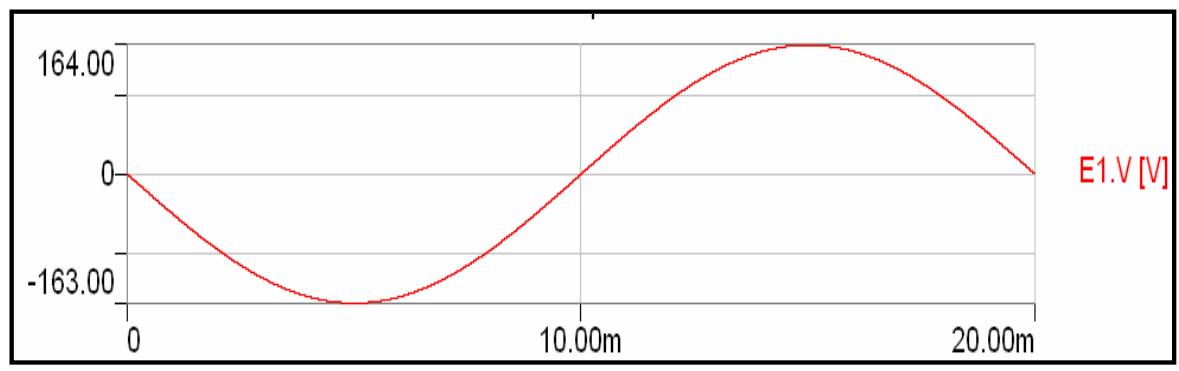

Fig. 20. Simplorer simulation of the AC input voltage of the two-stage converter in Fig. 19. 


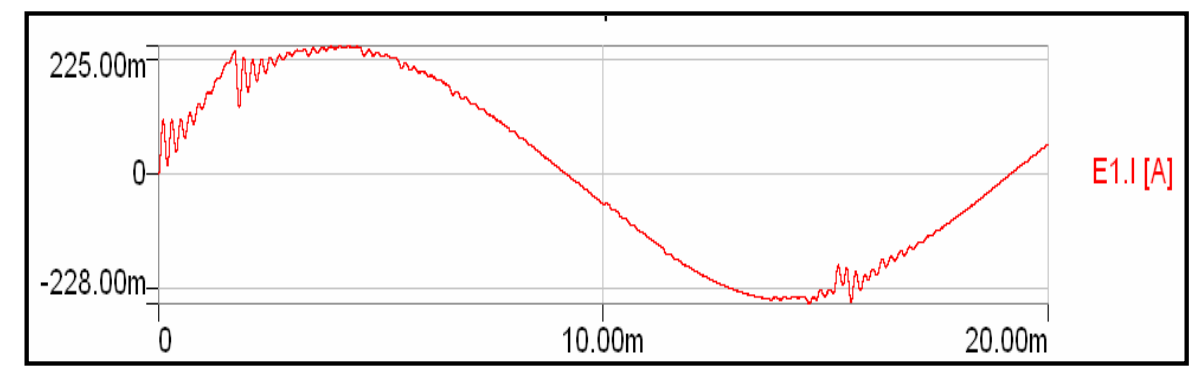

Fig. 21. Simplorer simulation of the AC input current of the two-stage converter in Fig. 23, including start-up.

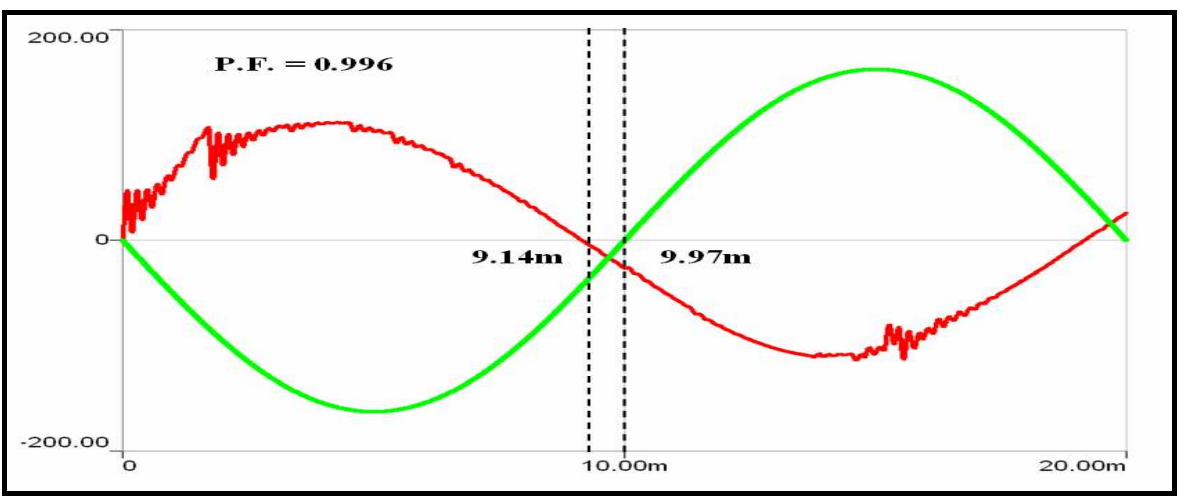

Fig. 22. Simulation results of input voltage (green line- smooth sinusoid) and input current (red line- with high frequency start-up ripple) together. Power factor is 0.996 in simulation.

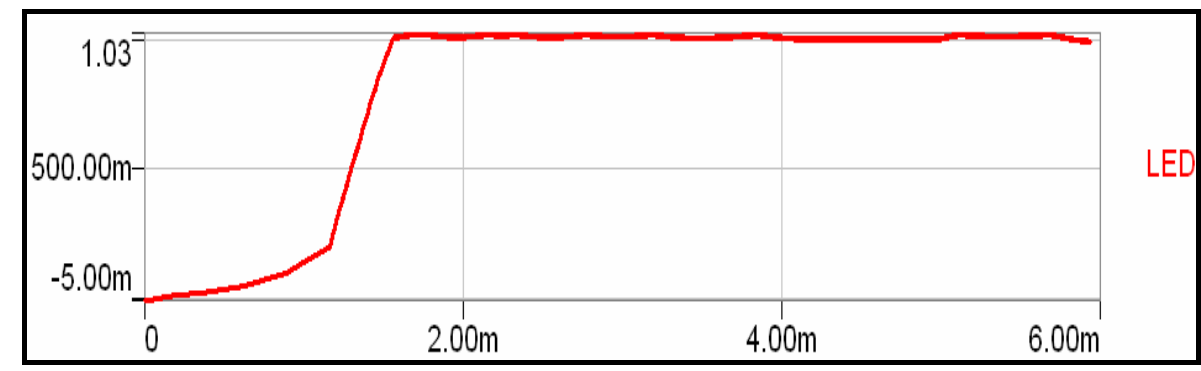

Fig. 23. Output LED Current for the Two Stage Converter, including start-up.

Figures 20, 21, 22 and 23 illustrate typical results of the SynDiTec digital core operating on the Two-Stage converter. In Fig. 21, it is seen that the start-up causes input current to oscillate, but after less than a quarter cycle, the input current becomes sinusoidal. Fig. 22 shows the input voltage and the input current in the same plot which indicates that the angular difference between the two waveforms is negligible. In this example, the power factor is simulated to be 0.996 and the total harmonic distortion is simulated to be $0.089 \%$. Once again, it should be remarked that these characteristics of high power factor and low THD were obtained without $\mathrm{A} / \mathrm{D}$ or D/A converters.

The output LED current is illustrated in Fig. 23. After a short start-up, the LED current reaches its desired DC steady state value. Thus the LED current is being accurately controlled to its desired reference. 


\section{Products Developed/Technology Transfer Activies}

\subsection{Publications}

1. Bhattacharya, A.; Lehman, B.; Shteynberg, A.; Rodriguez, H., "Digital Sliding Mode Pulsed Current Averaging IC Drivers for High Brightness Light Emitting Diodes" IEEE Computer in Power Electronics (COMPEL) 2006 held in Troy, New York.

IEEE COMPEL is one of the distinguished conferences in the field of power electronics. This conference brings together industrial, government, and academic researchers for interactive discussion on the latest advances in modeling, analysis, and control of power electronic devices, circuits, and systems. At COMPEL 2006, a special emphasis was on digital control of high-frequency converters as well as systems analysis, control, and power management. This paper was presented and well accepted by almost 100 industrial, government and academic researchers of power electronics field.

2. Bhattacharya, A.; Lehman, B.; Shteynberg, A.; Rodriguez, H., "Low cost digital LED driver without A/D or D/A converters" Submitted for IEEE APEC 2007

APEC is considered to be the leading conference for practicing power electronics professionals. The APEC program addresses a broad range of topics in the use, design, manufacture and marketing of all kinds of power electronics equipment.

\subsection{Web Site http://synditec.tripod.com}

\subsection{Networks or Collaborations Fostered}

The key strategy in getting to market lies in collaborating with partners to get designed into their overall package. The clearest path would appear to be to work with Lumileds Future Lighting, who can provide guidance and recommendations for what design specifications are most in demand within their supplier network.

Other options include working with leading companies such as GelCore or Color Kinetics, who could become lead customers through licensing or vendor relationships.

Table IV Target's Reason for Acquiring SynDiTec Technology

\begin{tabular}{|c|c|c|}
\hline Future Lighting & Color Kinetics & GelCo \\
\hline $\begin{array}{l}\text { Future Lighting is interested in } \\
\text { speeding the development and } \\
\text { deployment of LED lighting, and } \\
\text { to that end wishes to serve as a } \\
\text { catalyst in consolidating the } \\
\text { market. Future Lighting is } \\
\text { particularly interested in } \\
\text { promoting promising products }\end{array}$ & $\begin{array}{l}\text { Color Kinetics is on the lookout } \\
\text { for drivers which are low-cost, } \\
\text { properly address power } \\
\text { correction factor, and which can } \\
\text { handle higher input/output } \\
\text { voltages. }\end{array}$ & $\begin{array}{l}\text { GelCore is always interested in } \\
\text { lower-cost, higher-efficiency } \\
\text { products. Most of their drivers are } \\
\text { high current }(\sim 5 \mathrm{~A}) \text {, and operate } \\
\text { in a constant-voltage } \\
\text { configuration. They are also } \\
\text { interested in drivers with high } \\
\text { power factor. }\end{array}$ \\
\hline
\end{tabular}


The following table outlines the activities, milestones, and stakeholders are likely to be important for implementing the strategy outlined above. Stakeholders are individuals and institutions who should be (or must be) recruited to help in commercialization.

Table V

\begin{tabular}{|l|l|l|l|}
\hline Activity or Stakeholder & Importance & Milestone & $\begin{array}{l}\text { Suggested } \\
\text { Timeframe }\end{array}$ \\
\hline $\begin{array}{l}\text { TSMC, Power Semi } \\
\text { Manufacturing partner to produce } \\
\text { driver chips }\end{array}$ & Critical & $\begin{array}{l}\text { Finalize design, test of } \\
\text { manufactured driver chips. }\end{array}$ & Now \\
\hline $\begin{array}{l}\text { Lumileds Future Electronics } \\
\text { This initiative is coordinating the } \\
\text { Lumileds Luxeon line of LEDs with } \\
\text { the many suppliers of drivers, optics, } \\
\text { and thermal management solutions. }\end{array}$ & Critical & $\begin{array}{l}\text { Consult on design } \\
\text { specifications, with } \\
\text { particular focus on Future's } \\
\text { perspective of what would } \\
\text { be most interesting. }\end{array}$ & $\begin{array}{l}\text { As soon as } \\
\text { possible }\end{array}$ \\
\hline $\begin{array}{l}\text { Color Kinetics } \\
\begin{array}{l}\text { Leading LED integrator with record } \\
\text { of licensing technology from the } \\
\text { outside }\end{array}\end{array}$ & High & $\begin{array}{l}\text { Test followed by non- } \\
\text { exclusive license for HB- } \\
\text { LED lighting (general or } \\
\text { more broadly). }\end{array}$ & Soon \\
\hline $\begin{array}{l}\text { GelCore } \\
\text { Joint venture between GE lighting } \\
\text { and EMCORE, and likely to be a big } \\
\text { player. Most of their business is } \\
\text { currently focused on signals and } \\
\text { signage. }\end{array}$ & High & $\begin{array}{l}\text { Test followed by exclusive } \\
\text { license for drivers for } \\
\text { signals and signage, non- } \\
\text { exclusive for general } \\
\text { lighting. }\end{array}$ & Soon \\
\hline $\begin{array}{l}\text { Cree } \\
\text { Major competitor to Lumileds. }\end{array}$ & High & $\begin{array}{l}\text { Test followed by non- } \\
\text { exclusive license for HB- } \\
\text { LED lighting (general or } \\
\text { more broadly). }\end{array}$ & Soon \\
\hline
\end{tabular}

\subsection{Technologies/Techniques}

Overall, we demonstrated overwhelmingly the technical feasibility of Pulse Current Averaging Sliding Mode Control. Analytically and via mathematical simulations we showed for two operational input voltages, DC and AC that Pulse Current Averaging Hysteretic Control works to drive HB LED's. We consider we have made a theoretical contribution to Automatic Control Theory by investigating and developing a new digital pulse current averaging controller. That allows dropping traditional PWM or PFM feedback techniques and coming up with new suitable to digital implementation IC architecture. As the result, this controller is simple, low cost, and feasible for driving HB LED's as well as traditional switching power supplies loads. Some other advantages of this method appear to be:

- Inherent pulse-by-pulse current limiting, making the power converter nearly immune to damage from overload.

- No external compensation needed (low parts count). 
- Fast response of the inductor current.

- Automatic power factor correction in off-line drivers

- Robustness and increased noise immunity

- Programmable output current for brightness regulation and different compensation of drifting LED parameters.

\subsection{Other Products}

Although not one of the promised deliverables in the Phase I proposal, SynDiTec has actually designed, built and tested a working prototype that implements the SynDiTec digital core on an FPGA board. The board attempts to implement the diagram in Fig. 7, although the comparators and other analog components illustrated in the figure are separate external components on the board. (This is why the board is large $\left(5^{\prime \prime} \times 3^{\prime \prime}\right)$, and does not reflect in any way the size of the IC.)

Fig. 10 shows the prototype of the LED driver with digital controller. The FPGA is running the sliding mode pulsed current averaging IC Drivers, following the state machine in Fig. 7 and equations (1)-(3). The board can drive 8 LEDs maximum and the maximum current should be no more than 40mA. One potentiometer is used to SET the output current $: \mathrm{I}_{\mathrm{SET}}=0.200 / \mathrm{R}$. The nominal operating range of the input voltage is 2.5 7 Volts. 